\title{
A Reciclagem de PVC no Brasil
}

\author{
Ana Magda Piva, Miguel Bahiense Neto, Hélio Wiebeck
}

Resumo: Esta pesquisa discute as possibilidades práticas da reciclagem de PVC. Na reciclagem de polímeros, a do PVC representa uma importante parcela. PVC é um polímero que é usado em uma ampla faixa de produtos: filmes, fios, cabos, em compostos para uma variedade de formas. A reciclagem é uma técnica vantajosa, capaz de reproduzir as propriedades do polímero original, no polímero reciclado e isto em condições razoavelmente econômicas. A tecnologia brasileira, em relação a produtos reciclados, apresenta algumas diferenças da reciclagem tradicional. Métodos alternativos de reciclagens são necessários se os processos não desvalorizam os resultados finais.

Palavras-chave: Reciclagem mecânica, PVC, resíduo plástico, sucata, poluição.

\section{Introdução}

Em 1998, o Brasil consumiu mais de 600 mil toneladas da resina de PVC, isso representa $20 \%$ do total do consumo aparente de resina plástica consumida (considerando-se resinas de uso geral e de engenharia $)^{[1]}$. Essa imensa quantidade de resina PVC foi aplicada a artigos os mais variados, tais como: tubulações rígidas (para esgotos) e flexíveis, toalhas de mesa, cortinas, bolsas e roupas de "couro artificial", revestimentos de fios e cabos elétricos, pisos, brinquedos, sapatos, forração em geral, bolsas de sangue, manoplas, embalagens, filmes e placas em geral.

A cidade de São Paulo gera diariamente cerca de 13.000 toneladas de resíduos sólidos urbanos (não considerados os resíduos inertes), dos quais $5 \%$ são resíduos plásticos ${ }^{[2,3]}$ e deste percentual $6 \%$ é PVC. A disposição de cerca de $90 \%$ do total de resíduos sólidos coletados na cidade, portanto resíduo pós-consumo, é realizada em dois aterros sanitários: o Bandeirantes e o São João. Estes são os dois últimos locais remanescentes para a disposição adequada e de vida útil para apenas mais alguns anos. Este fato, por si só, já seria um incentivo a programas de coleta seletiva imediata, o que permitiria a obtenção de resíduos recicláveis com menor quantidade de impurezas, elevando seu valor de mercado ${ }^{[4]}$.

Apesar da conscientização ecológica, o material plástico reciclado ainda encontra muita resistência em sua aceitação pelo mercado. Os preconceitos quanto à utilização do plástico reciclado precisam deixar de existir, mesmo porque ele já é freqüentemente utilizado sem que sequer seja percebida sua origem. Produtos como botões pretos de fogões; tubos cinzas de chuveiros elétricos; roupas de poliéster em mistura com algodão; vassouras de cerdas plásticas; acessórios para automóveis, tais como calotas; e produtos para a agricultura, fazem parte de nosso dia-a-dia e são constituídos de plástico reciclado. 
Um mercado consolidado para produtos reciclados oferece a oportunidade de se obter grandes ganhos econômicos, tanto para a sociedade quanto para cada um dos segmentos envolvidos, sobretudo para a indústria. Atualmente, o mercado exige cada vez mais qualidade e regularidade no fornecimento da resina recuperada, o que mostra a incompreensão do contexto que vive a indústria de reciclagem nacional, que se percebe, muitas vezes, sem controle eficiente de sua própria produção ou da entrada de material a ser reciclado. A maioria dos recicladores de plástico constitui-se em empresas de pequeno porte, nas quais os altos impostos e a falta de subsídios influenciam de modo significativo sua continuidade. Nestas empresas a coleta seletiva representa uma fonte de matéria-prima de primeira necessidade. A reciclagem é uma atividade industrial e precisa de subsídios fortes para operar, assim como é realizado em países desenvolvidos, onde estas etapas já foram ultrapassadas e quem recicla inclusive exporta a resina recuperada ${ }^{[5]}$.

O caminho que proporciona a redução do consumo de materiais não renováveis, a minimização de resíduos, o aumento da vida útil dos locais de disposição final e contribui para a qualidade de vida e o desenvolvimento sustentado é incentivar e consumir produtos de plásticos recicláveis ${ }^{[6]}$.

O reaproveitamento de resíduos de material plástico, tanto os provenientes de processo industriall quanto aqueles advindos de produtos descartados pela sociedade (resíduos sólidos urbanos), tem se estabelecido de forma expressiva em três processos básicos que possibilitam a sua reciclagem após prévia triagem ${ }^{[2,7]}$. Dependendo da técnica utilizada, estes processos são conhecidos como de reciclagem mecânica, química ou energética.

Qualquer um dos processos de reciclagem acima citados não resolveria o problema da disposição final de resíduos na cidade, no entanto, poderiam contribuir a minimização, reduzindo a quantidade de resíduos a ser disposto ${ }^{[8,9]}$. No Brasil, a reciclagem mecânica ainda é o processo mais utilizado, estima-se que cerca de $15 \%$ dos resíduos plásticos pós-consumo, industriais ou agrícolas estão sendo reprocessados dessa maneira $^{[9,10]}$.

O processo conhecido como reciclagem mecânica consiste na combinação de um ou mais pro- cessos operacionais (moagem, aglomeração, granulação) para o reaproveitamento do resíduo plástico, transformando-o em grânulos, matéria prima para a fabricação de outros produtos.

A maioria dos produtos onde o PVC é aplicado, são de longa duração, isto é, possuem uma estimativa de vida útil maior que 40 anos $^{[11]}$. Esta estimativa de vida útil do PVC depende substancialmente da sua finalidade, pois a presença de vários aditivos lhe confere características não comuns a outros polímeros, tais como a mudança de propriedades com o tempo ou o aumento de elasticidade com a temperatura ${ }^{12}$. Estas características associadas às suas propriedades mecânicas, tornam o PVC atraente para a fabricação de artefatos de grande estimativa de vida útil, como perfis e tubos. Desta forma, apenas uma pequena parcela dessa resina retorna ao meio ambiente. No entanto, preocupados com o aspecto ecológico, o Instituto do PVC e o Departamento de Engenharia Química da Escola Politécnica da USP, realizaram uma pesquisa junto aos recicladores de PVC com o intuito de os localizar e verificar as dificuldades e necessidades deste setor. Este trabalho apresenta, também, um panorama de como os recicladores de PVC utilizam o fluxograma de reciclagem mecânica do PVC em seus diferentes tipos, em relação a um fluxograma normal ou tradicional de reciclagem mecânica. Além deste comparativo, são apresentados quais os processos mais utilizados para evitar o desgaste em equipamentos e minimizar custos.

\section{Metodologia aplicada a pesquisa}

Uma planilha com diversos itens foi preparada de forma a que fossem obtidas informações objetivas à respeito das características da matériaprima utilizada, como é obtida, mercado e proces$\mathrm{so}^{[15]}$. O levantamento das dificuldades encontradas pelo setor foi realizado entre 42 empresas recicladoras de material plástico da Região da Grande São Paulo. O método adotado incluia uma planilha com um questionário aplicado a cada empresa e espaço para observações de visita ao local da recicladora. O questionário constou de uma série de perguntas subdivididas em dois itens:

a) determinação do perfil da empresa: produção mensal, capacidade instalada, tipos de 
materiais utilizados na reciclagem, produtos obtidos, principais fontes de matéria-prima, equipamentos utilizados e consumo de aditivos, energia e água, entre outros;

b) dificuldades atuais da reciclagem de material plástico.

\section{Discussão dos resultados obtidos}

As respostas obtidas pelo instrumento enfatizaram os seguintes pontos:

$>$ o resíduo sólido urbano pode ser uma fonte confiável e constante para a reciclagem de plástico, se bem gerenciado;

$>$ a ausência da coleta seletiva e seu completo abandono;

$>$ a dificuldade na triagem e descontaminação dos resíduos plásticos;

$>$ os altos impostos para uma operação de reciclagem, tais como I.C.M. e I.P.I., além de sobretaxados;

$>$ a oscilação de preço no mercado;

$>$ a exigência de espaço físico para se trabalhar com resíduo sólido urbano;

$>$ a dificuldade de tratamento da água resultante da lavagem do resíduo sólido urbano;

$>$ a dificuldade de se efetuar a reciclagem com qualidade e constância;

$>$ a difícil classificação do grão plástico obtido; e

$>$ a geração de gastos extras ao processo devido à separação, seleção e classificação dos resíduos plásticos;

Os itens mais importantes observados foram:

$>$ A procedência do material a ser reciclado consiste em $40 \%$ de resíduo industrial e $60 \%$ de resíduo pós-consumo; os resíduos de pósconsumo, descartados no lixo, são resíduos captados em sucateiros e podem estar misturados a outras resinas ou contaminados com materiais orgânicos. Os resíduos pós-consumo são adquiridos por preço irrisório.

$>$ A dificuldade de obtenção de resíduo de PVC limpo, sem contaminação ou resíduo industrial; para as recicladoras, a utilização deste resíduo, ao invés daquele captado em sucateiros, tem como vantagem a constância na formulação, quantidade e a não contaminação com os mais diversos materiais como terra, vidro, trapos, alimentos, papéis e outros, além de diferentes tipos de resinas, que podem prejudicar o processo, como por exemplo, o PET, que contamina o processo de reciclagem do $\mathrm{PVC}$.

$>$ A quantidade de resíduo de PVC processado, que varia entre 4 e 150 toneladas/mês por empresa. Sendo que, $90 \%$ desses recicladores trabalham transformando o grão reciclado em produto acabado, tais como, tubos rígidos, mangueiras, sifões, eletrodutos, conexões, laminados e outros.

$\rightarrow$ A quantidade total (real) de PVC reciclado, na grande São Paulo, se estabelece numa faixa estimada ao redor de 700 t/mês

Percebe-se que a maioria dos recicladores evitam trabalhar com resíduo urbano sujo; o resíduo obtido limpo elimina a etapa de lavagem, que gera gastos com água, energia elétrica, mão-de-obra e efluentes poluentes.

No caso da reciclagem de PVC, foi constatado que, para compensar as perdas de propriedades do material reciclado, muitas vezes são acrescentados aditivos que encarecem o produto final, inviabilizando, na maioria das vezes, este procedimento. Esta nova incorporação de aditivos (concentrados de cor, plastificantes, estabilizantes térmicos e lubrificantes externos) é prática comum desses recicladores; a porcentagem adicionada de cada um deles depende do processo ou do resíduo.

O PVC é um material muito abrasivo e agressivo à vida útil dos equipamentos que o processam. Também foi questionado o motivo de ser o resíduo plástico, entre os materiais recicláveis, o único a pagar IPI.

As operações envolvidas no processamento de reciclagem convencional de plásticos é ilustrada na Figura 1 e constitui-se na: triagem para remoção de papéis, metais e outras partículas estranhas; moagem dos plásticos; lavagem com água contendo ou não detergentes; secagem e aglutinação; transformação em um artefato por processos convencionais de conformação em novos produtos ou extrusão e granulação.

Uma vez separado, por si só o PVC não apresenta nenhum problema para ser reprocessado. Atualmente, no Brasil, a reciclagem mecânica do PVC não misturado a outras resins é realizada para o PVC flexível e o PVC rígido. De forma geral, 


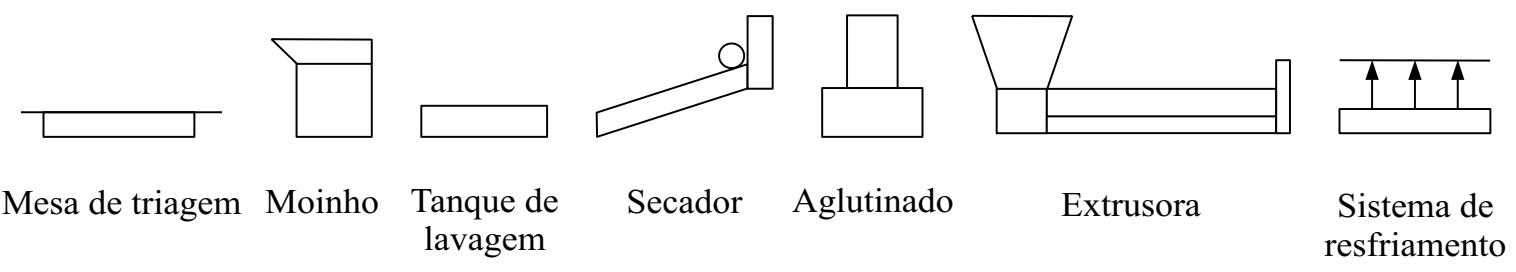

Figura 1. Fluxograma de reciclagem convencional ou tradicional de resíduos plásticos ${ }^{[13]}$.

estes compostos são divididos em três grandes grupos, de acordo a sua aplicação, em rígido, flexível e plastisol. Na reciclagem, no entanto, esta divisão em três grupos, incorpora uma, permanecendo apenas as designações de rígido e flexível que são diferenciadas pelos recicladores através do ensaio de dureza Shore A, desta forma:

$>$ Resíduo de PVC flexível: dureza abaixo de 90 de Shore A

$>$ Resíduo de PVC rígido: dureza acima de 90 Shore A

São poucas as empresas no Brasil que reciclam plastisol ou produtos conformados de plastisol.

Uma das dificuldades do processamento do resíduo não misturado de PVC são as perdas por degradação do material, que pode ser evitada através de uma nova incorporação de aditivos. No entanto, estes aditivos aumentam o custo final do produto, tornando-se prática comum a adição de pequena parcela de um outro resíduo que contenha o aditivo necessário. Ao ser reciclado um artefato de PVC, os recicladores em sua maioria, não levam em conta que este já contém uma série de aditivos, que podem ou não interferir no reprocesso, como por exemplo os estabilizantes à base de zinco, que causam manchas pretas no produto reciclado rígido ao ser reprocessado.

O resíduo ou sucata de PVC flexível (dureza abaixo de 90 Shore A) tem seu fluxograma de reciclagem mecânica semelhante ao apresentado na Figura 1, em que a moagem é o primeiro passo; a lavagem faz-se necessária, principalmente se o resíduo for urbano e estiver sujo ou contaminado, normalmente este esse procedimento é evitado; a etapa de secagem faz-se necessária a fim de reduzir a umidade do PVC, que deve ser processado com teor menor que $1 \%$, para que possa seguir o seu fluxo no processo de extrusão. No aglutinador, o material se aglomera formando partículas maiores, aumentando sua densidade aparente (relação massa por volume). É comum os recicladores aproveitarem esse equipamento para completar a secagem do PVC. A adição de plastificantes como o DOP, também é muito utilizada e tem como objetivo promover um ajuste na dureza do produto a ser obtido.

A extrusão do PVC exige máquina robusta, de boa qualidade mecânica e, no mínimo, com tratamento de nitretação nas partes internas (roscas e paredes do cilindro) para evitar corrosão. Mesmo com os tratamentos exigidos para a rosca da extrusora, seu desgaste é inevitável devendo ser "recalibrada" ou sofrer recobertura pelo menos duas vezes ao ano, dependendo da quantidade de material extrusado. Se este procedimento preventivo não for seguido, perde-se em produtividade, qualidade do produto e têm-se aumentado o consumo de energia, além de danificar-se o equipamento, gerando custos extras de produção.

O corte do material é feito na extrusora (saída do equipamento), que produz o chamado "espaguete" (através de um molde perfurado), a ser "picotado" posteriormente no granulador. $\mathrm{O}$ uso de um trocador de telas automático é importante para o processo, mas não é imprescindível. Geralmente, trabalha-se com zonas de aquecimento variando entre 150 e $220^{\circ} \mathrm{C}$. O "espaguete" é, então, resfriado. Esta etapa é realizada nas chamadas calhas ou banheiras de resfriamento, que utilizam água fria (ou a temperatura ambiente). Após o resfriamento, o material é "picotado" em grânulos de tamanho padronizado ( $3 \mathrm{~mm}$ ), em um granulador (picotador), que trabalha com facas de corte muito sensíveis. Esta etapa determina o fim do processo e o material é, então, embalado e estocado. Dependendo de suas características, o material reciclado pode ser conformado por injeção ou extrusão, obtendo-se como produtos finais solados em geral, manoplas, mangueiras, e outros.

Os resíduos de PVC rígido, quando tem sua origem na indústria são, geralmente, por elas próprias reprocessados. Quando sua procedência é de sucateiros e outros, encontram-se, muitas vezes, contaminados com outras resinas. Um dos piores problemas de contaminação no processo de 
reciclagem é o apresentado pelas resinas $\mathrm{PVC}$ e PET. Ambas as resinas possuem densidade ${ }^{14} \mathrm{em}$ torno de $1,3-1,35 \mathrm{~g} / \mathrm{cm}^{3}$ e, portanto, não são separáveis pelo método de decantação convencional. Portanto, sua identificação fica a cargo das características de cada material e da acuidade visual dos funcionários designados a essa função. Se o PET estiver contaminado com PVC, este se degradará durante o processamento do PET, devido à sua elevada temperatura de processo. Entretanto, se o PET estiver contaminando o PVC, deverá ser eliminado do processo, por filtração, porque ele não funde à temperatura de processo do PVC.

A reciclagem do PVC rígido é bastante simples quando o resíduo é "limpo". As etapas de lavagem e secagem são suprimidas. Usualmente o resíduo é moído, o pó gerado é recuperado, retornando ao processo junto ao material moído. Este material, de acordo com a sua característica e/ou de acordo com o que se deseja produzir, é aditivado em uma moega e, usualmente, enviado de forma direta para uma extrusora ou injetora.

Apesar da conhecida sensibilidade térmica do PVC rígido, ele pode ser reprocessado; em alguns casos têm-se a adição de estabilizantes ou lubrificantes à formulação a ser reciclada.

O produto reciclado tem, entre outras aplicações, sido utilizado na conformação de conduítes elétricos e tubos para baixa pressão. A produção de tubos é sensivel a contaminações com papel, poliestireno e polietileno que alteram as propriedades físicas das peças produzidas. Podem ser processados em blendas para cabos, "coberturas" para parede e perfis de janelas.

Assim, as mudanças realizadas no fluxograma de processo convencional, tanto para a reciclagem do PVC flexível, quanto para a do PVC rígido, resumem-se na retirada das etapas, quando possível, de lavagem e aglutinação, enviando o material diretamente para a extrusora ou diretamente para a injetora. Existem recicladores que seguem o fluxograma convencional, incorporando, no entanto, outros resíduos de forma a baratear o custo de produção.

\section{Conclusões}

As mudanças no fluxograma convencional de reprocesso do resíduo, de forma a baratear o custo da operação, não comprometem o desempenho do produto, no entanto, exigem mais cuidados na manipulação dos resíduos e na escolha da fonte.

Os fatores que tornariam a reciclagem economicamente viável referem-se à obtenção de melhores informações técnicas e à diminuição das dificuldades do aparelhamento administrativo governamental, sobretudo uma avaliação de viabilidade econômica da reciclagem sob um ponto de vista macro, estimulando esta atividade potencial para a promoção de desenvolvimento em termos de geração de renda, emprego e equilíbrio ambiental, economicamente e socialmente sustentável, com a vantagem de se estar economizando energia, água, matéria-prima e reduzindo a poluição ambiental e os problemas de saúde pública decorrentes.

Sem o devido incentivo a recuperação do material plástico dos resíduos sólidos urbanos deixa de ter interesse como um negócio, pois além de causar problemas de contaminação ambiental e gerar efluentes líquidos com alto teor de poluentes, não existem equipamentos modernos que propiciem uma maior lucratividade, seja pela falta de tecnologia nacional, seja pela falta de subsídio governamental como a criação de linhas de crédito específicas para a indústria de reciclagem ou incentivos fiscais ou ainda pelas dificuldades apresentadas durante o reprocessamento do material, que muitas vezes, exige a incorporação de aditivos, encarecendo o produto final.

\section{Agradecimento}

Este trabalho faz parte do projeto FAPESP 95/5044-0

\section{Referências Bibliográficas}

1. Anuário da Indústria Química Brasileira. São Paulo, ABIQUIM (1998).

2. Schwarz, L. B. - "Reciclagem: Vida Longa Para Plásticos", Polímeros - Ciência e Tecnologia, out/dez (1995).

3. Wiebeck, H.; Angeletakis, A. R.; Schwarz, L. B. - "A Reciclagem de Plásticos na Grande São Paulo", anais do $10^{\circ}$ Congresso Brasileiro de Engenharia Química, p. 525-539 (1994). 
4. Günter, W. R.; Wiebeck, H.; Piva, A. M. - "Quanto a Necessidade de Incentivo a Reciclagem de Plástico", Revista Limpeza Pública, mar (1999).

5. Agnelli, J. A. M. - "Reciclagem de Polímeros: Situação Brasileira", Polímeros: Ciência e Tecnologia, p. 9-18, out/dez (1996).

6. Fouhy, K. et all - "Plastics Recycling Diminishing Return", Chemical Engineering, p. 3034, dez (1993).

7. Ehrig, R.J. - "Plastics Recycling: Products and Processes", Hanser, N. York, (1992).

8. Mustafa, N. - "Plastics Waste Management Disposal, Recycling”, Marcel Dekker, N. York, (1993).

9. Coronado, J. - "Incineração dos Resíduos Plásticos Pode Gerar Energia”, Plástico Moderno, ago (1996).
10. Furtado, M.R. - "Aplicações Novas Prometem Dobrar o Uso do Reciclado", Plástico Moderno, jun. (1996).

11. Saeki, Y. - "Challenges of Waste Towards the $21^{\text {th }}$ Century", International Polymer Process XIII, (1993).

12. Sousa, W. - "Setor Recicla Preconceitos", Plástico Moderno, maio (1993).

13. Pinto, A. G. - "Reciclagem de Outros Componentes - Plásticos", In: Lixo Municipal Manual de Gerenciamento Integrado, IPT, São Paulo, (1995).

14. Mano, E. B. - "Polímeros como Materiais de Engenharia", ed. Edgard Blüchert, (1996).

15. Wiebeck, H.; et all - "Dificuldades na Reciclagem do Plástico do Resíduo Sólido Urbano do Lixão" anais do III Congresso Brasileiro de Polímeros, p. 1183-86, Salvador, Bahia, Brasil, (1997). 